\title{
Primary Infection, Lesion Productivity, and Survival of Sporangia in the Grapevine Downy Mildew Pathogen Plasmopara viticola
}

\author{
Megan M. Kennelly, David M. Gadoury, Wayne F. Wilcox, Peter A. Magarey, and Robert C. Seem
}

First, second, third, and fifth authors: Department of Plant Pathology, Cornell University, New York State Agricultural Experiment Station (NYSAES), Geneva 14456; and fourth author: South Australian Research and Development Institute, Loxton Research Centre, Loxton 5333.

Current address of M. M. Kennelly: Department of Plant Pathology, Kansas State University, Manhattan 66506.

Accepted for publication 25 October 2006.

\begin{abstract}
Kennelly, M. M., Gadoury, D. M., Wilcox, W. F., Magarey, P. A., and Seem, R. C. 2007. Primary infection, lesion productivity, and survival of sporangia in the grapevine downy mildew pathogen, Plasmopara viticola. Phytopathology 97:512-522.

Several aspects of grapevine downy mildew epidemiology that are fundamental to model predictions were investigated. Simple rainfall-, temperature-, and phenology-based thresholds (rain $>2.5 \mathrm{~mm}$; temperature $>11^{\circ} \mathrm{C}$; and phenology $>$ Eichorn and Lorenz [E\&L] growth stage 12) were evaluated to forecast primary (oosporic) infection by Plasmopara viticola. The threshold was consistent across 15 years of historical data on the highly susceptible cv. Chancellor at one site, and successfully predicted the initial outbreak of downy mildew for 2 of 3 years at three additional sites. Field inoculations demonstrated that shoot tissue

also found that oospores may continue to germinate and cause infections throughout the growing season, in contrast to the widely-held assumption that the supply of oospores is depleted shortly after bloom. Lesion productivity (sporangia/lesion) did not decline with age of a lesion in the absence of suitable weather to induce sporulation. However, the productivity of all lesions declined rapidly through repeated cycles of sporulation. Extremely high temperatures (i.e., one day reaching $42.8^{\circ} \mathrm{C}$ ) had an eradicative effect under vineyard conditions, and permanently reduced sporulation from existing (but not incubating) lesions to trace levels, despite a later return to weather conducive to sporulation. In fair weather, most sporangia died sometime during the daylight period immediately following their production. However, over $50 \%$ of sporangia still released zoospores after 12 to $24 \mathrm{~h}$ of exposure to overcast conditions.
\end{abstract} was susceptible to infection as early as E\&L stage 5, suggesting that initial germination of oospores, rather than acquisition of host susceptibility, was probably the limiting factor in the initiation of disease outbreaks. We
Additional keywords: epidemiology, forecasting, disease management.
Downy mildew of grapevine, caused by the oomycete Plasmopara viticola (Burk. \& Curt.) Berl. \& de Toni, is a widespread and destructive disease of Vitis spp., particularly in viticultural areas with high annual rainfall $(5,24)$. Interactions of the pathogen with host phenology, temperature, humidity, surface wetness, and light are complex throughout the disease cycle. This complexity makes the disease ideally suited for computer-based modeling, which can integrate multiple variables to identify infection periods and forecast disease severity. DMCast is one such model previously described by Park et al. (29), and there are many others $(2,6,16,25,26,32,33)$.

$P$. viticola is a heterothallic oomycete (36) and overwinters as oospores in leaf litter in vineyard soils. Oospores germinate in spring to produce a macrosporangium which releases zoospores. Macrosporangia or zoospores, separately or in combination, are splashed by rain into the grapevine canopy where they swim to and infect through stomata (5). The original DMCast model (29) predicted outbreaks of primary infection based on oospore maturity (35). In contrast, in many viticultural regions various simplified rules are used to forecast the first occurrence of primary infection. These rules typically involve thresholds for host

Corresponding author: M. M. Kennelly; E-mail address: kennelly@ksu.edu

* The $\boldsymbol{e}$-Xtra logo stands for "electronic extra" and indicates that Figures 1,2, and 5 appear in color online.

doi:10.1094/PHYTO-97-4-0512

(C) 2007 The American Phytopathological Society development (e.g., shoots longer than $10 \mathrm{~cm}$ ), rainfall (e.g., greater than 8 to $10 \mathrm{~mm}$ ), and temperature (e.g., greater than $\left.10^{\circ} \mathrm{C}\right)(27,32,33)$. Gehmann (9) calculated that oospores are mature when degree-day accumulation reaches a total of 170 (base ${ }^{\circ} \mathrm{C}$ ) starting from January 1 , and infection occurs with the first 10 $\mathrm{mm}$ rain that follows. However, in other studies oospores were found to be mature as early as January 28 , well before the 170 degree-day threshold was reached (34). It has been assumed that stomata on shoots less than $10 \mathrm{~cm}$ long are not yet functional, and therefore cannot accommodate infection by zoospores (33). In Australia, oospores are considered to be always present, and the grapevine to be always susceptible (26). Based upon historical records of weather and first-observed disease on the highlysusceptible Vitis interspecific hybrid cv. Chancellor in Geneva, NY, a comparable set of simplified rules was developed for use in DMCast $(7,8)$. These rules stated that once vines reach Eichorn and Lorenz (E\&L) growth stage 12 (five to six leaves unfolded, cluster clearly visible but still compact [30]), the first primary infections occur after a rainfall of at least $2.5 \mathrm{~mm}$ coincident with temperatures $\geq 11^{\circ} \mathrm{C}$. However, the susceptibility of shoots younger than E\&L stage 12 had not been assessed experimentally, nor had the above rules (derived from data in a single vineyard) been validated across multiple sites.

After the initial primary infection event, sporangia produced by foliar lesions are thought to drive the epidemic via repeated cycles of secondary infection $(2,4,26,29)$. However, several recent reports $(10,11,23)$ suggest that oospores can contribute to epidemic progress throughout the season. The conditions for oosporic infection differ significantly from those for sporangial infection $(5,24)$, particularly with the requirement of nighttime high humid- 
ity for the latter. Therefore, any model focused exclusively on sporangial inoculum would ignore weather events uniquely suitable for oospore infection. The frequently-observed resurgence of downy mildew in New York in late summer following a period of inactivity has been attributed to a return of weather more favorable for secondary disease development (7). However, the potential for an extended season of oospore germination and infection remains poorly understood.

As lesions age they become necrotic and nonproductive (5). Hill (14) and Zachos (38) observed repeated sporulation from individual foliar lesions, with some remaining viable and productive for 2 to 3 months. However, it remains unclear when, under what conditions, and to what degree such productivity declines or is maintained. Our preliminary experiments suggested that sporulation cycles and lesion age, separately or in combination, could affect sporangial production (19-22).

In addition to declining lesion activity, sporangia themselves decline in viability over time. Sporangia have been reported to die within $15 \mathrm{~min}$ in direct sunlight (38) or to survive at least 10 days in a $15^{\circ} \mathrm{C}$ humid chamber (17). Many forecasting models $(25,26,29,33)$ use data from a laboratory study of Blaeser and Weltzien (1) to estimate survival of sporangia under vineyard conditions. However, field validation data to support such applications are lacking.

Accurate forecasting is dependent upon an equally accurate understanding of the various factors that impact the disease cycle. Though grapevine downy mildew has been studied extensively since it first spread throughout Europe in the late 1800s, there remain critical aspects of both primary and secondary infection that are poorly understood and which limit our ability to forecast the disease. For example, at what stage of host development, and under what environmental conditions, is an epidemic initiated in spring? For how long into the season do oospores contribute to the epidemic? What is the relationship between environmental factors and the longevity and productivity of sporulating lesions? Our overall goal in the following study was to answer the above questions, and to thereby improve the knowledge base upon which DMCast and similar forecasting systems are founded. Thus, the objectives were to (i) validate the above criteria in forecasting the initial appearance of downy mildew; (ii) determine if $P$. viticola can infect shoots before E\&L stage 12 is reached; (iii) determine how long into the season oospores continue to cause infection; (iv) quantify the impact of lesion age and repeated cycles of sporulation on the longevity and productivity of foliar lesions; and (v) monitor and quantify the survival of sporangia in vineyards.

\section{MATERIALS AND METHODS}

Evaluation of predictive model for primary infection. Records of grapevine phenology, daily rainfall, temperature, and the date of first-observed symptoms of downy mildew were obtained for a vineyard of the Vitis interspecific hybrid Chancellor at the New York State Agricultural Experiment Station (NYSAES) at Geneva for the years 1981, 1983, and 1985 to 1997 (Table 1). In those years, 240 to 300 flower clusters on 12 to 15 unsprayed Chancellor vines were examined for symptoms of downy mildew every 1 to 5 days, beginning approximately 3 weeks before bloom. Chancellor clusters are extremely susceptible to downy mildew,

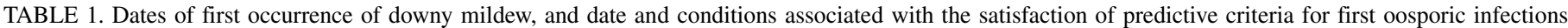
(Eichorn and Lorenz growth stage $\geq 12$, rainfall $>2.5 \mathrm{~mm}$, temperature $>11>{ }^{\circ} \mathrm{C}$ ) during 1981-2004

\begin{tabular}{|c|c|c|c|c|c|c|c|c|c|}
\hline \multicolumn{4}{|c|}{ First symptoms ${ }^{\mathrm{w}}$} & \multicolumn{6}{|c|}{ Environmental conditions to which primary infection was attributed ${ }^{\mathrm{x}}$} \\
\hline Year & Site & Date & $\begin{array}{l}\text { Growth } \\
\text { stage }^{y}\end{array}$ & Date & $\begin{array}{l}\text { Growth } \\
\text { stage }\end{array}$ & $\begin{array}{c}\text { Rain } \\
\text { (millimeters) }\end{array}$ & $\begin{array}{c}\text { Temperature } \\
\left(0^{\circ} \mathrm{C}\right) \\
\text { during rain }\end{array}$ & $\begin{array}{c}\text { Incubation } \\
\text { days }\end{array}$ & $\begin{array}{c}\text { Degree days } \\
\text { (base }=0^{\circ} \mathrm{C} \text { ) between } \\
\text { infection and } \\
\text { symptom detection }\end{array}$ \\
\hline 1981 & Geneva & 17 June & $2 \mathrm{~d}$ postbloom & 11 June & 19 & 2.5 & 16.7 & 6 & 196 \\
\hline 1983 & Geneva & 15 June & Bloom & 7 June & 15 & 8.1 & 12.2 & 8 & 151 \\
\hline 1985 & Geneva & 18 June & Bloom & 12 June & 19 & 30.2 & 12.8 & 6 & 115 \\
\hline 1986 & Geneva & 6 June & Bloom & 1 June & 12 & 3.8 & 18.3 & 5 & 93 \\
\hline 1987 & Geneva & 23 June & $10 \mathrm{~d}$ postbloom & 13 June & 21 & 8.9 & 20.0 & 10 & 211 \\
\hline 1988 & Geneva & 16 June & $1 \mathrm{~d}$ prebloom & 2 June & 12 & 7.6 & 15.0 & 14 & 252 \\
\hline 1989 & Geneva & 14 June & $7 \mathrm{~d}$ prebloom & 6 June & 12 & 4.3 & 15.0 & 8 & 143 \\
\hline 1990 & Geneva & 14 June & $6 \mathrm{~d}$ prebloom & 9 June & 12 & 6.4 & 17.8 & 5 & 92 \\
\hline 1991 & Geneva & 4 June & $3 \mathrm{~d}$ prebloom & 31 May & 19 & 10.4 & 25.0 & 4 & 76 \\
\hline 1992 & Geneva & 14 June & $7 \mathrm{~d}$ prebloom & 8 June & 12 & 3.6 & 21.1 & 6 & 120 \\
\hline 1993 & Geneva & 21 June & Bloom & 10 June & 15 & 4.3 & 22.2 & 11 & 224 \\
\hline 1994 & Geneva & 14 June & $3 \mathrm{~d}$ prebloom & 1 June & 12 & 27.7 & 21.7 & 13 & 221 \\
\hline 1995 & Geneva & 13 June & 7 d prebloom & 3 June & 12 & 13.5 & 22.2 & 10 & 175 \\
\hline 1996 & Geneva & 9 June & $10 \mathrm{~d}$ prebloom & 24 May & 12 & 9.1 & 15.6 & 16 & 272 \\
\hline 1997 & Geneva & 16 June & $12 \mathrm{~d}$ prebloom & 7 June & 12 & 3.0 & 18.9 & 9 & 177 \\
\hline 2001 & Geneva & 11 June & 17 & 1 June & 12 & 3.3 & 13.4 & 10 & 166 \\
\hline 2001 & Wayne & 12 June & 17 & 1 June & 12 & 2.5 & 13.1 & 12 & 185 \\
\hline 2001 & Dundee & 12 June & 17 & 1 June & 12 & 2.5 & 13.1 & 12 & 185 \\
\hline 2001 & Ovid & 12 June & 17 & 1 June & 12 & 3.3 & 11.8 & 11 & 168 \\
\hline 2001 & Watkins & 20 June & Bloom & 1 June & 12 & 2.5 & 13.1 & 19 & 371 \\
\hline 2002 & Geneva & 10 June & $15-17$ & 29 May & 12 & 19.1 & 20.6 & 13 & 209 \\
\hline 2002 & Watkins & 12 June & 17 & 29 May & 12 & 17.8 & 11.2 & 14 & 253 \\
\hline 2002 & Dundee & 14 June & 17 & 29 May & 12 & 17.8 & 11.2 & 16 & 286 \\
\hline 2002 & Wayne & 14 June & 17 & 29 May & 12 & 14.2 & 21.7 & 16 & 286 \\
\hline 2003 & Geneva & 9 June & $12-15$ & 31 May & 9 & 19.6 & 11.4 & 9 & 122 \\
\hline 2003 & Wayne & 9 June & $12-15$ & 31 May & 9 & 18.3 & 11.9 & 9 & 121 \\
\hline 2003 & Watkins & 12 June & $15-17$ & 31 May & 9 & 15.0 & 11.4 & 12 & 193 \\
\hline 2003 & Dundee & No disease $\mathrm{z}^{\mathrm{z}}$ & & & & & & & \\
\hline 2004 & Geneva & 27 May & $15-17$ & 21 May & 12 & 4.1 & 15.8 & 6 & 90 \\
\hline
\end{tabular}

${ }^{\mathrm{w}}$ First appearance of symptoms, determined by visual assessment of epinasty and confirmed by sporulation in the laboratory.

${ }^{x}$ Probable infection event as determined by weather records, vineyard observations, and probable incubation period.

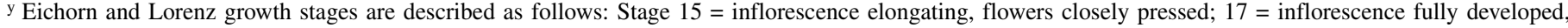
flowers separating; 19 = beginning of flowering; and 21 = early flowering, $25 \%$ of caps fallen.

z Symptoms had not appeared as of 20 June, and monitoring was discontinued. 
and they display a distinctive and readily-detected epinasty following infection by $P$. viticola. Using the reported data, a set of criteria was developed $(7,8)$ to forecast the date of initial primary (oosporic) infection of grapevine by $P$. viticola (i.e., first occurrence of a rain greater than $2.5 \mathrm{~mm}$ with average temperature $>11^{\circ} \mathrm{C}$, after the date of E\&L stage 12).

The above criteria were evaluated regionally from 2001 to 2003 in four commercial Chancellor vineyards in the Finger Lakes region of New York (near the towns of Watkins Glen, Wayne, Ovid, and Dundee) in addition to the Chancellor vineyard in Geneva where the original data used to develop the criteria were collected. The Geneva vineyard was monitored again in 2004. Starting before vines reached E\&L growth stage 12, flower clusters on vines at the commercial vineyard sites were examined for symptoms of downy mildew every 2 to 7 days and the growth stage was recorded. At these sites disease was assessed on nine to 11 contiguous unsprayed vines, and in Geneva, disease was assessed on an equivalent number of unsprayed vines scattered within a 0.25 ha vineyard. Symptomatic clusters were harvested and placed in a moist chamber in darkness to induce sporulation and to confirm presence of the pathogen. Rainfall and temperature data for each site were collected at the nearest available weather stations (approximately 2, 20, 4, 16, and $13 \mathrm{~km}$ from the Geneva, Watkins Glen, Wayne, Ovid, and Dundee sites, respectively). The criteria were evaluated by comparing expected and observed dates of infection.

Susceptibility during early stages of shoot growth. We inoculated 4 to 10 shoots on unsprayed vines of the Vitis interspecific hybrid cvs. Delaware and Chancellor and on $V$ vinifera Chardonnay at E\&L growth stage 7 (first leaf unfolded

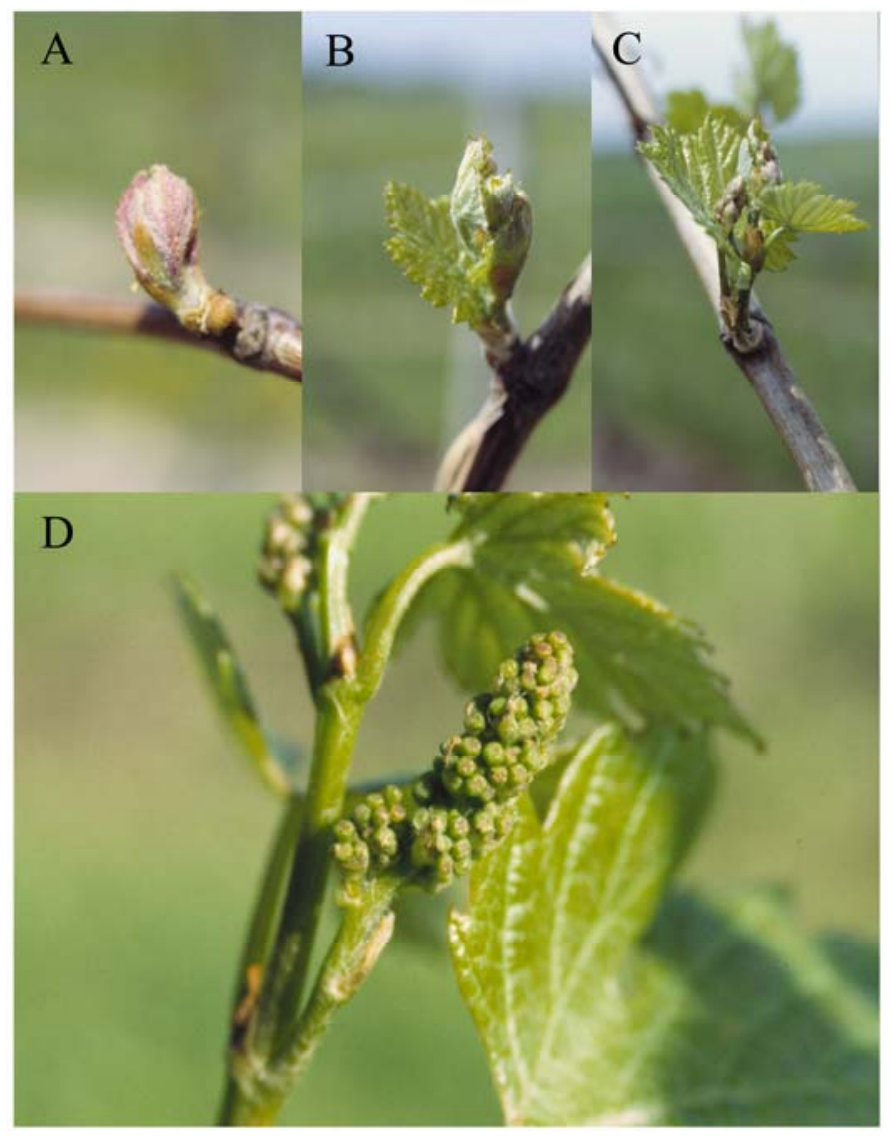

Fig. 1. Eichorn and Lorenz growth stages of grapevine referred to in inoculation studies. A, Stage 5: bud burst, green shoot first clearly visible. B, Stage 7: first leaf unfolded and spread away from the shoot. C, Stage 9: two to three leaves unfolded. D, Stage 12: five to six leaves unfolded, inflorescence clearly visible but not yet elongated. and spread away from shoot) or 9 (two to three leaves unfolded) in Geneva in 2003 (Fig. 1). A hand-held spray bottle was used to apply a distilled water suspension of freshly-produced sporangia $\left(5 \times 10^{4}\right.$ sporangia per $\mathrm{ml}$ of water) to entire shoots (leaf, flower, and stem tissues). Still attached to the vine, each shoot was then enclosed in a wet plastic bag overnight (12 to $14 \mathrm{~h}$ ) to maintain adequate surface wetness for infection. Inoculations were performed just before sunset to avoid overheating of the bagged shoots, and only when forecast temperatures for the coming night were above $10^{\circ} \mathrm{C}$. Bags were removed from the shoots shortly after sunrise the next morning. Disease development was assessed 14 days after inoculation by spraying the shoots with distilled water, enclosing them in plastic bags overnight in the vineyard, and assessing the incidence of sporulation on all parts of the shoot the next morning. The experiment was performed twice in 2003 on the above three cultivars, and once in 2004 on seven to nine shoots of Chardonnay vines inoculated at E\&L stages 5 (bud burst, shoot first clearly visible), 7 , and 9 (Fig. 1). The experiment was repeated again in 2005 by inoculating six shoots at E\&L stages 5, 7, and 9 on each of three Chardonnay and $V$. vinifera Riesling vines.

Seasonal maturation and germination of oospores. In May 2004 we collected topsoil from beneath the grapevine canopy in a Delaware vineyard in Geneva that was severely defoliated by downy mildew in 2003. The soil was redistributed to a depth of $2 \mathrm{~cm}$ in three 2-m-square plots in a grassy area more than $1 \mathrm{~km}$ from any vineyard. The grass in the plots was killed with glyphosate (The Scotts Company, Marysville, $\mathrm{OH}$ ). During a series of 3- to 7-day intervals between 20 May and 20 October 2003 we placed 10 open-pollinated $V$. vinifera seedlings in each soil plot. Starting 7 September we placed wire cages over plants to prevent deer grazing. After exposure in the field plots, the seedlings were transferred to a screen house, incubated for 1 to 2 weeks, placed in a moist chamber overnight to induce sporulation, and then examined the next day under a stereomicroscope at 10 to $25 \times$ to detect $P$. viticola sporulation and recorded incidence of downy mildew.

The experiment was repeated in 2005 with the following modifications. New soil was gathered from the same Delaware vineyard immediately before bud break, and distributed on killed turf as described above at a location approximately $75 \mathrm{~m}$ from the 2004 soil plot site. Three identically-sized plots consisting of killed turf alone with no vineyard soil served as controls. Beginning on 24 May, 10 open-pollinated $V$. vinifera seedlings were placed in each plot. The seedlings were removed after each rain event, incubated in a screenhouse for 2 weeks, treated as described above to promote sporulation, and examined for signs of the pathogen at $20 \times$ magnification the next day. The percentage of seedlings supporting sporulation on one or more leaves in each plot was recorded.

Beginning on 1 August 2005, we also deployed 10 seedlings per plot in each of the three infested-soil plots that were used in 2004. Our intent was to determine if oospores could survive in soil for more than one growing season. Following rain events, these seedlings were removed, incubated, and examined as above. The last group of seedlings was deployed in all plots on 23 September 2005, and was processed as described above following a rain event 4 days later.

Longevity and sporangial productivity of foliar lesions. Experiments were conducted in two Delaware vineyards in Geneva in 2002 and at a single Chardonnay vineyard in Loxton, South Australia, in 2003. Cohorts (groups of lesions initiated in the same infection period) of naturally-occurring foliar lesions were used to create additional cohorts of lesions by inoculating leaves as described above for young shoot infection. Naturally-occurring cohorts of lesions were selected based upon daily examinations of shoots for newly-symptomatic leaves (i.e., light-yellow, nonsporulating lesions on a previously asymptomatic leaf). Lesions on 
naturally infected and inoculated leaves were labeled with a permanent marker to allow later identification.

Within each experiment we induced sporulation either in the field or laboratory. In the field, leaves were misted with distilled water and enclosed in plastic bags overnight while still attached to the vine. The next morning, sporangia from each lesion were washed into a vial, the volume of water used was measured, and the number of sporangia per lesion was determined with the aid of a hemacytometer. For sporulation in the laboratory, we collected the leaves from the vineyard and incubated them in a wet plastic bag at room temperature in darkness. The next day we excised each lesion with a razor blade, shook it in a known volume of water, and enumerated the sporangia using a hemacytometer. We also estimated lesion area by taking the average of two diameters (measured to the nearest millimeter).

The effect of latent period upon sporangial production levels was investigated in Loxton in 2003. Three distinct cohorts of lesions served as repetitions of the experiment. The cohorts were established by inoculating leaves on Chardonnay vines on 22, 24, and 30 October as described above. When symptoms appeared 1 week later, lesions were marked as described above for future collection. Local weather was dry and thus there was no natural sporulation in the vineyard. For each cohort we collected two lesions per shoot on each of four to five shoots at 9 to 11,16 to 18 , and 22 to 25 days after inoculation. Leaves bearing lesions were picked and incubated in the laboratory, and the sporangia were enumerated as described above. One $80-\mu l$ droplet of sporangial suspension from each lesion was placed in a closed plastic petri dish, incubated for $4 \mathrm{~h}$ at 20 to $25^{\circ} \mathrm{C}$, and then 10 sporangia per drop were examined microscopically to determine if they had germinated (i.e., released zoospores). On 15 November 2003 the outdoor temperature in Loxton reached $42.8^{\circ} \mathrm{C}$, with $4 \mathrm{~h}$ above $40^{\circ} \mathrm{C}$, which effectively killed the pathogen within the lesions in the cohorts. No further sporulation could be induced, and there were no further collections of lesions beyond day 24. Treatment effects were analyzed by regression of the number of sporangia produced against lesion age.

The impact of successive sporulation events upon productivity of individual lesions that arose from natural infection events was assessed in Geneva in 2002. Four distinct cohorts representing lesions that became macroscopically visible on 27 June, 16 July, 2 August, and 8 August were identified and marked. Each cohort consisted of 8 to 12 lesions distributed among several shoots of unsprayed Delaware vines. Sporangia were produced by induction every 1 to 8 days in the field, as described above, or in response to weather conducive to sporulation. Sporangia were enumerated as above. Sampling continued until the lesions no longer produced detectable levels of spores.

To compare lesions that supported different absolute quantities of sporulation, the level of sporulation per lesion at each sporulation event was scaled to the maximum observed for that lesion, which usually occurred at the first sporulation, to give relative sporulation. Relative sporulation of all four cohorts was pooled after analysis for homogeneity of variance. To develop a general model describing the decline of sporulation by lesions during successive sporulation events, the natural logarithm of relative spore production was regressed against the numerical sequence of the event (Minitab Release 10.51 Xtra, State College, PA). The experiment was repeated in Loxton in 2003 with the following modifications: Three cohorts of lesions were established by inoculating eight shoots on Chardonnay vines on 22, 24, and 30 October. Each cohort was then divided, and lesions were induced to sporulate in the vineyard at approximately 1-, 2-, 4-, or 8-day intervals by misting and enclosing shoots in plastic bags. After the prescribed sporulation events one lesion from each shoot (eight lesions per cohort) was excised with a razor blade, measured, placed in a known volume of water, shaken, and the sporangia per square millimeter were determined with a hemacytometer. All le- sions remaining on the leaves in the field were washed with water so that sporangia collected at the next sampling event would be newly generated. Following high temperatures on 15 November no further sporulation could be induced on our leaves, and the experiment was ended.

Survival of sporangia under vineyard conditions. These experiments were carried out in Loxton in 2003 in the previouslydescribed Chardonnay vineyard. Temperature, relative humidity (RH), and surface wetness were monitored by electronic sensors located within the grapevine canopy at the research site, and were recorded at 10-min intervals by a CR10 datalogger (Campbell Scientific Inc., Logan, Utah). Five cohorts of shoots were inoculated as described above. Once the latent period had passed, sporulation was induced in each cohort by placing wet plastic bags on the shoots overnight as previously described, removing the bags just after sunrise on 4, 5, 6, and 13 November, and on 4 December 2003, and then collecting samples of sporangia after cutting a $1-\mathrm{cm}$ disk of sporulating tissue from one leaf per shoot at 1- to 4-h intervals throughout the following day. Preliminary experiments had indicated that sporangia allowed to rehydrate in a humid atmosphere for 15 to 30 min germinated at a much higher frequency than those transferred immediately into water after being exposed to low $\mathrm{RH}$, and that sporangia in small, discrete droplets germinated at a much higher frequency than those submerged in higher volumes of water in closed vials. Therefore, each disk collected above was placed in a humid chamber for 15 to $30 \mathrm{~min}$ to allow gradual rehydration before sporangia were rinsed from the disks with distilled water. Several $80-\mu$ l droplets of the resulting suspension were applied by pipette into a closed plastic petri dish in discrete spots. Viability of sporangia was assessed microscopically at $400 \times$ after 3 to $4 \mathrm{~h}$ incubation at $21^{\circ} \mathrm{C}$, and again after at least 20 more h. For each assessment, a total of at least 100 sporangia per replicate leaf disk were observed and the number of germinated (empty) sporangia were recorded, as well as whether the released zoospores were still motile or had encysted.

The experiment was modified and carried out using 1-year-old potted Chardonnay vines. The potted vines were inoculated in the greenhouse and incubated throughout the latent period as above. The vines were then placed in wet plastic bags overnight to induce sporulation. Before sunrise the next morning, the potted vines were removed from the bags, allowed to dry in the laboratory for $10 \mathrm{~min}$, and then entire plants were securely placed into the canopy of mature vines within the above Chardonnay vineyard, with the shoots of the potted vine entirely within the canopy of the field vines. A total of two to six potted vines were deployed in the vineyard on 4-6, 20, and 28 November, and 4 December 2003. Sporangia were collected and viability was assessed as described for shoots on field-grown vines.

\section{RESULTS}

Validation of criteria to predict the date of initial oosporic infection. The first occurrence of a rain greater than $2.5 \mathrm{~mm}$ with average temperature $\geq 11^{\circ} \mathrm{C}$, after the vines had reached an average E\&L stage 12, was followed by the appearance of downy mildew symptoms 9 to 19 days later for all 10 of the site/year combinations examined in 2001, 2002, and 2004 (Table 1). In contrast, vines at the three sites where disease developed in 2003 already displayed symptoms when they reached E\&L stage 12 . Thus, it appears that they became infected during a rainfall at E\&L stage 9 more than a week earlier.

The cumulative degree days (base $0^{\circ} \mathrm{C}$ ) from 1 January to 1 June in 2001, 2002, and 2003 were 811, 862, and 729, respectively.

Susceptibility during early stages of shoot growth. Shoots were highly susceptible to infection when inoculated earlier in development than E\&L stage 12 (Fig. 2 and Table 2). The average 
incidence of disease across the four cultivars inoculated at E\&L stages 7 and 9 was 76.0 and $83.7 \%$, respectively, and on more than $50 \%$ of the shoots sporulation was observed on both leaves and flower clusters. The mean incidence of disease among Chardonnay shoots inoculated at E\&L stage 5 in 2003 was $28.6 \%$. The mean incidence of disease on Chardonnay shoots inoculated at E\&L stages 5, 7, or 9 in 2005 was 88.6, 77.7, and 66.3\%, respectively. For Riesling shoots inoculated at E\&L stages 5, 7, or 9 in 2005 , the mean incidence of disease was $77.3,83.3$, and $60.6 \%$, respectively. On both Chardonnay and Riesling, sporulation was observed simultaneously on stem tissue, leaves, tendrils, and flower clusters following inoculation at all of the preceding stages on more than $30 \%$ of the inoculated shoots.

Maturation and germination of oospores. Grapevine seedlings placed on the relocated vineyard soil developed downy mildew during rain events from May 20 to October 4, 2004. The first infections in 2004 were noted on seedlings deployed during a rain event on 21 May (Table 3), which also caused the first oosporic infections in the Chancellor vineyard in Geneva (Table 1). More than $30 \%$ of the seedlings commonly became infected following rain events through mid-September, and the highest incidence of infection occurred among seedlings deployed during 25 August to 15 September 2004 (Table 3). Similar results were obtained in 2005 when new seedlings were placed into these plots or into additional plots over relocated soil collected at the beginning of the 2005 growing season (Table 3). In no case did nearby control seedlings placed over killed sod develop downy mildew.

Longevity and productivity of foliar lesions. The length of the latent period did not affect the quantity or quality of sporangia

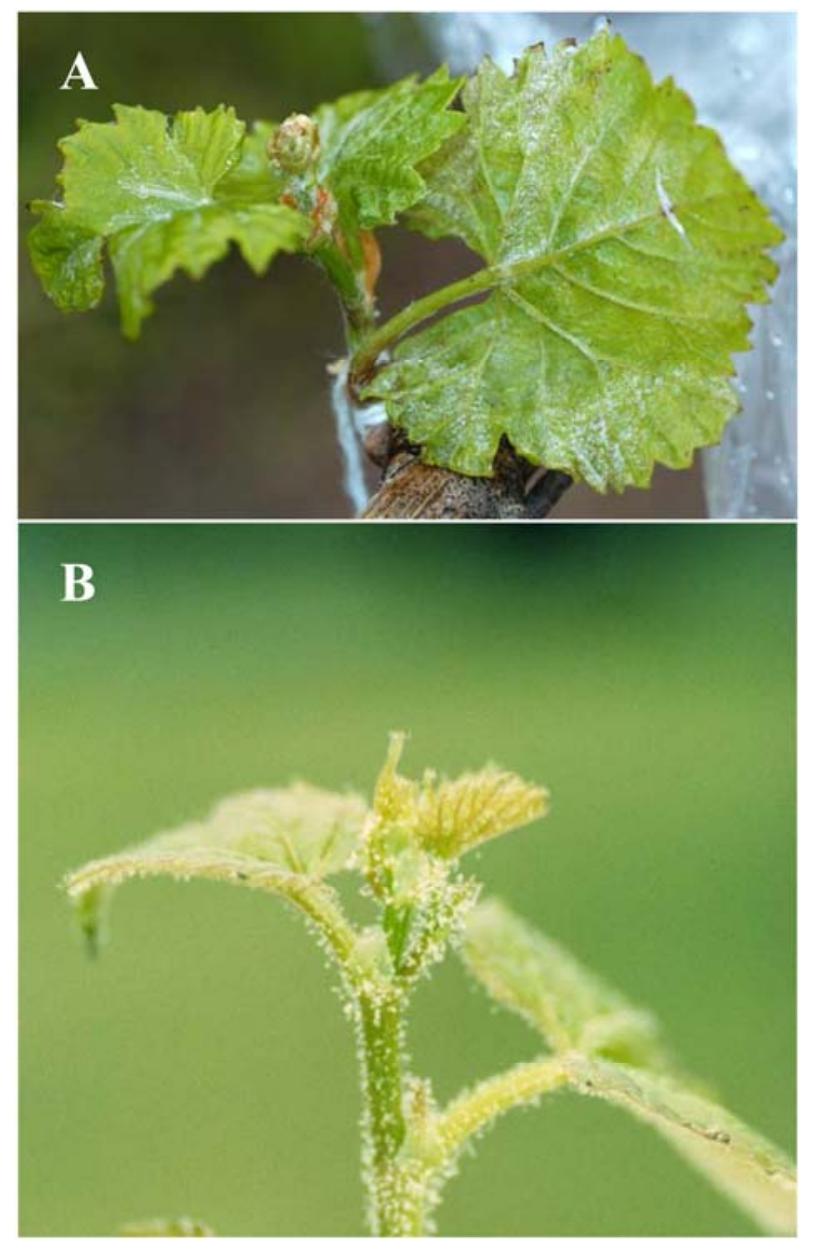

Fig. 2. Sporulation of Plasmopara viticola on grapevine shoots inoculated at Eichorn and Lorenz growth stage 7 (one leaf unfolded) at A, one week; and B, two weeks after inoculation. produced on foliar lesions. Lesions that sporulated for the first time 3 weeks after inoculation produced numbers of sporangia not significantly different from those that first sporulated 1 week after inoculation $(P=0.53)$. Delaying initial sporulation also had no significant effect upon viability of the sporangia produced $(P=$ 0.89 ). An average of 96 and $93 \%$ of sporangia were viable in 9- to 10- and 22- to 24-day-old lesions, respectively.

Once the latent period had passed, the number of times a lesion sporulated had a strong effect on subsequent productivity of lesions. Cohorts of lesions sporulated at high levels one to three times, and sporangial production decreased sharply thereafter (Fig. 3). Regression of the natural logarithm of relative sporulation observed during an event against the numerical order of the sporulation event yielded equation 1:

$Y=4.757-0.496 X$

where $Y$ equals $\ln$ [relative sporulation $(\%)+1$ ]

and $X$ equals the numerical order of the sporulation event;

$\mathrm{R}^{2}$ was equal to 0.77 .

This same principle was illustrated when lesions of the same age that had produced different numbers of sporulation cycles were examined. In the cohort of lesions created on 22 October 2003, those sporulating for the eighth time on 13 November produced less than one-fifth as many sporangia per square millimeter as lesions that were sporulating for the first time (Fig. 4A). Lesions that were sporulating for the first time on 13 November following initiation on 24 October produced more than twice as many as those that had already sporulated once, and more than five times as many as those that were sporulating for the fourth time (Fig. 4B). Similar results were obtained for a cohort of lesions that was initiated on 30 October and induced to sporulate for either the first, second, or fourth time on 14 November (Fig. 4C).

Most lesions that were visible, but had not yet sporulated on 15 November 2003 when the high temperature reached $42.8^{\circ} \mathrm{C}$ (average temperature from 8:00 a.m. to 8:00 p.m. was $36.9^{\circ} \mathrm{C}$ ) lost the capacity to do so. These lesions possessed the yellow appearance typical of lesions with a high potential for sporulation, and retained this appearance throughout repeated attempts to induce subsequent sporulation. The more than 100 leaves in the above cohort produced zero to trace numbers of sporangia when exposed to conditions favorable for sporulation over a period of 25 days following 15 November. In contrast, leaves that were inoculated on 13 November, but had not yet expressed symptoms

TABLE 2. Susceptibility of grapevine shoots to Plasmopara viticola when inoculated at Eichorn Lorenz growth stages 5, 7, and 9

\begin{tabular}{lccc}
\hline Year & Cultivar & $\begin{array}{c}\text { Growth stage at } \\
\text { inoculation }\end{array}$ & $\begin{array}{c}\text { Disease } \\
\text { incidence }\end{array}$ \\
\hline 2003 & Delaware & 7 & 100.0 \\
2003 & Delaware & 9 & 100.0 \\
2003 & Chancellor & 7 & 28.6 \\
2003 & Chancellor & 9 & 75.0 \\
2003 & Chardonnay & 7 & 100.0 \\
2003 & Chardonnay & 9 & 100.0 \\
2004 & Chardonnay & 5 & 28.6 \\
2004 & Chardonnay & 7 & 66.6 \\
2004 & Chardonnay & 9 & 100.0 \\
2005 & Chardonnay & 5 & $88.6(8.01)$ \\
2005 & Chardonnay & 7 & $77.7(7.54)$ \\
2005 & Chardonnay & 9 & $66.3(13.47)$ \\
2005 & Riesling & 5 & $77.3(5.68)$ \\
2005 & Riesling & 7 & $83.3(6.94)$ \\
2005 & Riesling & 9 & $60.6(5.34)$ \\
\hline
\end{tabular}

${ }^{z}$ Shoots were inoculated at the indicated growth stages. Disease was assessed 14 days after inoculation. Disease incidence represents the percentage of shoots supporting any sporulation. Number in parentheses is the standard error. The 2003 and 2004 trials do not include a standard error because the inoculations were only performed one time on four to ten (2003) or seven to nine (2004) shoots per cultivar/growth stage combination. 
by 15 November, expressed the normal progression of symptoms (i.e., yellow, circular spots which progressively became necrotic) and yielded abundant sporangia after standard incubation (Fig. 5).

Survival of sporangia under vineyard conditions. Germination of sporangia increased only slightly between 4 and $20 \mathrm{~h}$ after immersion in water. Regression of the natural logarithm of germination frequency after $4 \mathrm{~h}$ of immersion against that at $20 \mathrm{~h}$ yielded the equation 2 :

$Y=-2.24+0.87 X$, where $Y$ equals the percentage of sporangia germinating after $4 \mathrm{~h}$ immersion and $X$ equals the percentage of sporangia germinating after $20 \mathrm{~h}$ immersion; $\mathrm{R}^{2}$ was equal to 0.83 and standard error (SE) of $\beta 0$ and $\beta 1=6.01$ and 0.01 , respectively. Thus, subsequent analyses of germination were performed using data collected after $4 \mathrm{~h}$ of immersion. Motile zoospores were observed for up to $7 \mathrm{~h}$ beyond the time that $100 \%$ of sporangia had germinated, considerably longer than the 30-min motile period reported by Gregory (12). Coefficients of regression for sporangial viability over time were not significantly different among cohorts of lesions on leaves of field-grown grapevines and those on potted vines placed within field-grown canopies $(P>$ $0.446)$, and these data were pooled for subsequent analyses. On 5 days with similarly clear skies and warm, dry weather (average high temperature $30.6^{\circ} \mathrm{C}, \mathrm{SE}=1.2$ ) and average $\mathrm{RH}$ of $24 \%$ (SE $=1.9$ ), viability of sporangia (as measured by their ability to germinate within $4 \mathrm{~h}$ ) decreased significantly in the first few hours after sunrise, and no sporangia were viable after 6 to $8 \mathrm{~h}$ of exposure (Fig. 6).

However, during cooler, more humid weather (average high temperature of $24.4^{\circ} \mathrm{C}$ [SE $=5.2$ ] and average $\mathrm{RH}$ of $86.6 \%$ [SE = $6.2]$ ), the sporangial viability decreased only modestly during the 8-h exposure (Fig. 7). The slope of the regression of the natural logarithm of the percentage of germinating sporangia against time of exposure was not significant $(P=0.59$, Fig. 7A; $P=0.276$, Fig. 7B). DMCast's sporangial survival model tended to overpredict spore viability during the course of the day in both the sunny and overcast conditions experienced during our testing (Figs. 6 and 7). Regression of observed germination against that predicted by DMCast (based upon hourly temperature and relative humidity at the vineyard research site) for all days yielded equation 3:

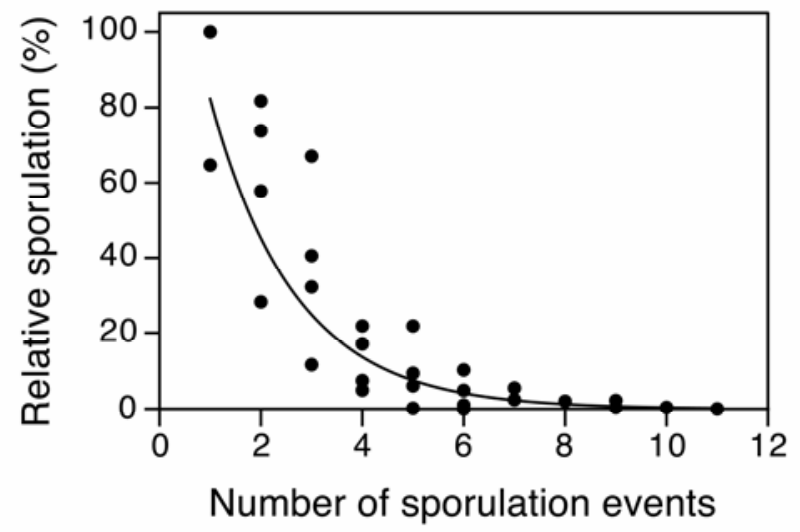

Fig. 3. Decline of sporangial production with successive sporulation events. Production of sporangia was assessed on cohorts of lesions induced to sporulate repeatedly. For each lesion, sporulation during the event in which the maximum was observed was set to $100 \%$, and sporulation during other events was scaled to that maximum to calculate relative sporulation. Each data point represents the mean response for one cohort. Curve fitted to the observations was generated by equation $1(\mathrm{Y}=4.757-0.496 \mathrm{X})$ after $\ln +1$ transformation of the response variable.

TABLE 3. Infection of grape seedlings by Plasmopara viticola placed over relocated vineyard soil in 2004 and 2005

\begin{tabular}{|c|c|c|c|c|}
\hline Year soil collected & Year seedlings exposed & Interval of exposure & $\begin{array}{l}\text { Number of infection events } \\
\text { during exposure of seedlings }\end{array}$ & Incidence of infection $(\%)^{\mathrm{z}}$ \\
\hline \multirow[t]{18}{*}{2004} & 2004 & $21-24$ May & 1 & $43.3(31.8)$ \\
\hline & & $18-22$ June & 1 & $46.3(15.9$ \\
\hline & & $23-25$ June & 1 & $13.3(8.2)$ \\
\hline & & $26-28$ June & 1 & $33.8(25.4)$ \\
\hline & & 31 July - 4 Aug & 1 & $68.1(6.4)$ \\
\hline & & $14-18$ Aug & 1 & $31.8(20.2)$ \\
\hline & & $19-25$ Aug & 1 & $3.3(4.1)$ \\
\hline & & $26-31$ Aug & 2 & $83.3(20.4)$ \\
\hline & & $8-15$ Sept & 2 & $88.8(0.6)$ \\
\hline & & $16-20$ Sept & 2 & $1.1(1.4)$ \\
\hline & & 30 Sept -6 Oct & 1 & $0.7(0.8)$ \\
\hline & 2005 & $10-13$ June & 1 & $40.3(10.8)$ \\
\hline & & $24-30$ June & 1 & $77.7(7.8)$ \\
\hline & & 7 - 18 July & 2 & $66.3(13.3)$ \\
\hline & & $15-22$ Aug & 1 & $26.7(3.3)$ \\
\hline & & 31 Aug -12 Sept & 1 & $77.2(5.5)$ \\
\hline & & $15-19$ Sept & 1 & $66.7(8.8)$ \\
\hline & & $23-27$ Sept & 2 & $23.3(3.3)$ \\
\hline \multirow[t]{14}{*}{2005} & 2005 & $24-26$ May & 1 & $13.3(3.3)$ \\
\hline & & $27-31$ May & 1 & $16.7(6.7)$ \\
\hline & & 3 - 10 June & 1 & $6.7(3.3)$ \\
\hline & & $10-13$ June & 1 & $26.7(3.3)$ \\
\hline & & $13-17$ June & 2 & $23.3(8.8)$ \\
\hline & & $24-30$ June & 1 & $36.7(6.7)$ \\
\hline & & 7 - 18 July & 2 & $46.7(8.8)$ \\
\hline & & $18-28$ July & 1 & $6.7(3.3)$ \\
\hline & & 28 July -15 Aug & 2 & 46.7 (18.6) \\
\hline & & $15-22$ Aug & 1 & 51.7 (15.9) \\
\hline & & $22-31$ Aug & 1 & $20.0(5.8)$ \\
\hline & & 31 Aug -12 Sept & 1 & $20.0(0.0)$ \\
\hline & & $15-19$ Sept & 1 & 36.7 (21.9) \\
\hline & & $23-27$ Sept & 2 & $21.7(7.3)$ \\
\hline
\end{tabular}

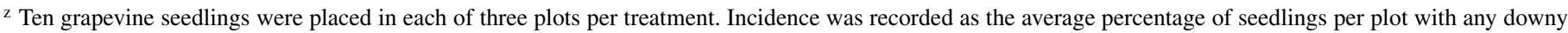
mildew infection. Number in parentheses displays the standard error. 
$Y=-1.46+0.764 X, \mathrm{R}^{2}=0.73$, where $Y$ equals the observed percent germination of sporangia and $X$ the percent germination predicted by DMCast for the time of that observation (Fig. 8).

\section{DISCUSSION}

Although complex, environmentally-driven models have been suggested to predict the maturity, development, and depletion of the oosporic inoculum $(4,29,32,35)$, we found that simple phenology-, rainfall-, and temperature-based guidelines accurately identified the first primary infection event of the season in most years. Though grapevine phenology is correlated with degree-day accumulation, the primary infection dates predicted by Gehmann's (9) 170 degree-day/10 $\mathrm{mm}$ rain criteria ranged from 30 days too early to 21 days too late in this study. Changing the rainfall threshold to $2.5 \mathrm{~mm}$ did not improve predictions using Gehmann's model (9). Additionally, the delay of initial oosporic infection until after E\&L growth stage 12 was not due to lack of susceptibility of shoots at earlier stages, as had been suggested in
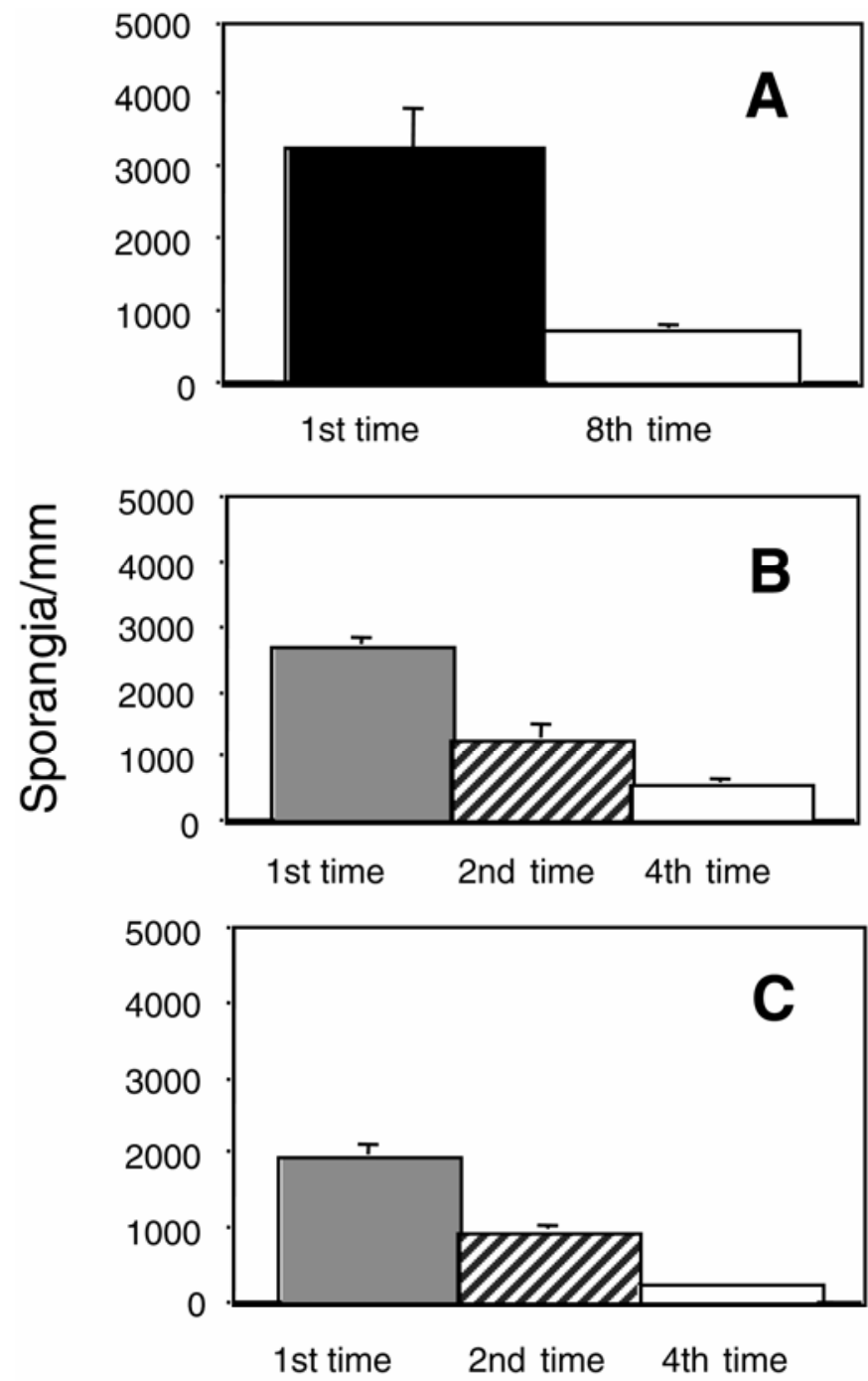

\section{Number of times sporulated}

Fig. 4. Sporangial production at 16 to 24 days after inoculation among lesions sporulating for the first, second, fourth, or eighth time. Cohorts of lesions were created by inoculations on A, 22; B, 24; and C, 30 October. After the latent period had passed, cohorts were induced to sporulate at approximately 1-, 3-, 6-, or 8-day intervals. Bars represent spore production by lesions on (A, B) 13 and on (C) 14 November. Error bars indicate one standard error of the mean. previous studies $(29,33)$. In fact, shoots were susceptible to infection as early as E\&L stage 5, shortly after bud break. It appeared that initial oospore germination was generally coincident with E\&L stage 12. However, our 2003 results showed that oospores sometimes caused infection as early as E\&L stage 9. Spring 2003 was unusually cool, and the cumulative degree days from 1 January to 1 June in 2003 totaled 729, compared to an average of 901.3 (SE 32.6) during the years 1998 to 2004 (excluding 2003). How this cooler weather may have influenced the development of oospores relative to budbreak of grapevines remains unknown. However, to account for the possibility of earlier oosporic infection E\&L stage 9 should be used as the phenological stage at which rainfall and temperature are monitored to forecast oosporic infection. Doing so would result in minimal changes to the forecasted date of primary infection reported in Table 1, as E\&L stages 9 and 12 are separated by an average of 3.6 days for the years reported in Table 1 .

The results of using seedling trap plants suggest that the distribution of oospore maturity and germination is far broader than had been reported in some earlier studies $(4,29,31)$ and that many oospores retain the ability to germinate throughout the growing season. Furthermore, using relocated vineyard soil showed that a substantial number of oospores may survive for more than one growing season. This is consistent with microsatellite analysis of inoculum sources in Europe $(10,11)$ and the United States (23) reporting that oospores can survive more than a year in the laboratory under both wet (38) and dry (13) conditions, and studies of the baiting of zoospores from vineyard soils (3). Survival of oospores for more than one growing season has been reported for other oomycetes, e.g., Phytophthora cactorum (15).

The protracted period of oospore maturation and germination is relevant to the forecasting of downy mildew epidemics and practical management of the disease with fungicides. Several previous models of grapevine downy mildew assumed a discrete period of primary infection, after which epidemics were assumed to be driven by production of sporangia and consequent secondary infection cycles. The environmental requirements for oosporic germination and infection (i.e., a threshold quantity of rainfall coincident with moderate temperatures) differ substantially from the more complex chain of circumstances required for secondary infection (i.e., temperature and moisture conducive not only to the nocturnal production of sporangia, but also their subsequent survival and dispersal, zoospore release, and infection). The simpler requirements for oosporic infection might be met more frequently than those for secondary infection, and thus during much of the growing season oospores could cause infections that are not currently considered by most forecast models and which trigger further unexpected secondary spread.

The season-long predominance of unique genotypes in recent microsatellite analyses of downy mildew epidemics has been attributed to a paucity of secondary spread of disease $(10,11)$. Seasonal survival and germination of oospores, especially our findings that oospores can survive more than one growing season, provides an alternative mechanism by which novel genotypes might continue to predominate in collections of isolates made throughout an epidemic under certain conditions. For example, oosporic inoculum dose from the previous season or seasons could outweigh the contribution of extant lesions to epidemic development in vineyards with a history of poor disease control with abundant oospores in the soil, particularly during weather that does not favor long-term survival of sporangia and/or lesions.

We found that the longevity and productivity of foliar lesions was linked to how often they were induced to sporulate. Hill (14) reported that sporangial production decreased markedly within 10 days after symptom appearance. Indeed, when induced to sporulate at 1- to 2-day-intervals, a decline of nearly $90 \%$ in the number of sporangia produced over a 10-day period was ob- 
served. However, in the absence of an opportunity to sporulate or extremely high temperatures, lesions typically maintained their maximum potential to produce sporangia for at least 22 to 24 days. The decline in sporangial production over sequential episodes of sporulation was associated with increased necrosis until only sparse marginal sporulation was supported (Fig. 5). The number of cycles of sporulation was the principal factor involved in the declining production of sporangia over time in our study. Both Hill (14) and Zachos (38) reported some sporulation on 2- to 3 -month old lesions, although the sporulation history and absolute

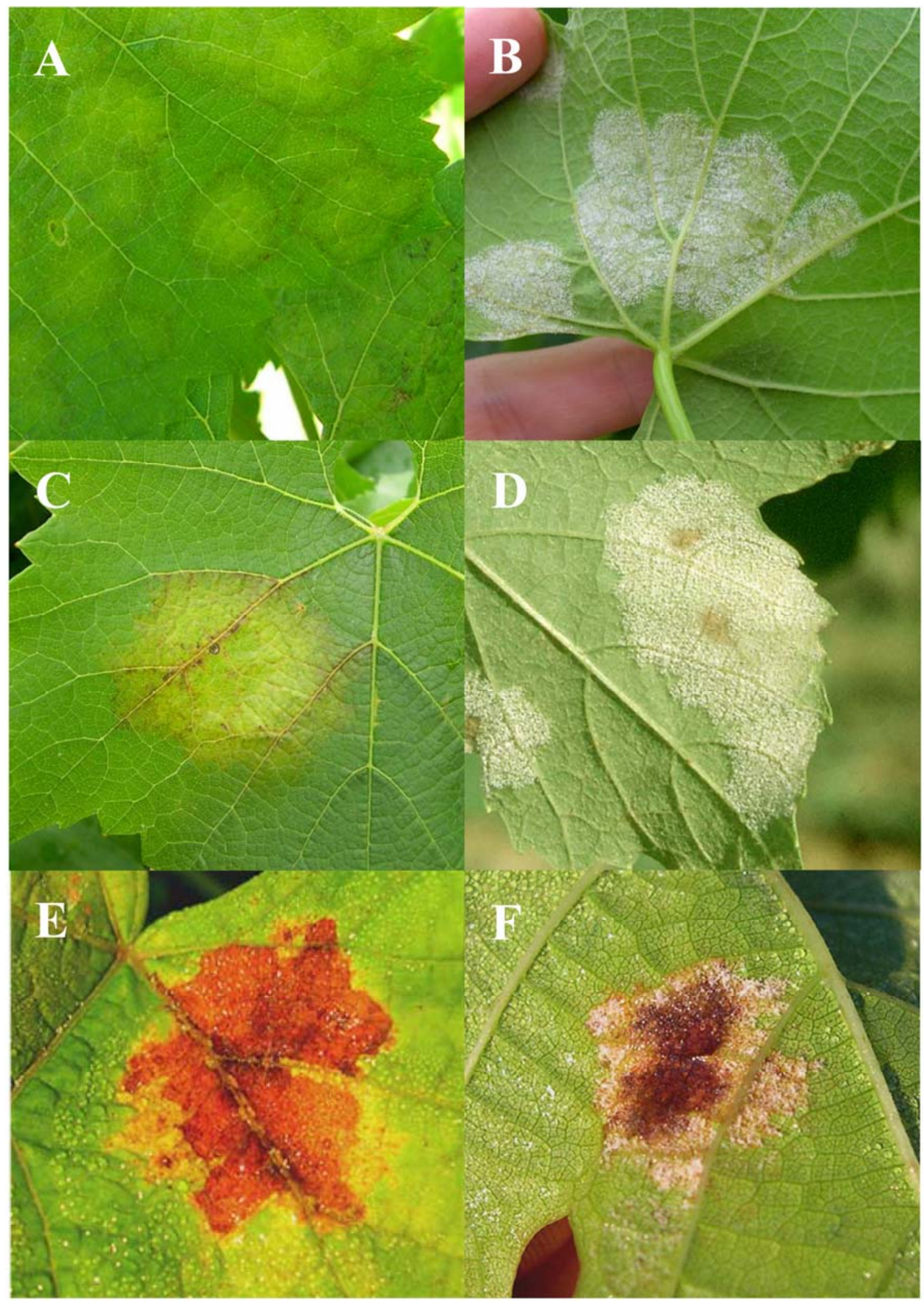

Fig. 5. Sequence of lesion development and sporulation of Plasmopara viticola on grapevine leaves. A, Yellow leafspot (oilspot) adaxial surface symptom common to newly-sporulating lesions with little to no epidermal necrosis. B, Profuse sporulation from tissues underlying such lesions. C, Beginnings of necrosis in lesion after two sporulation events. D, Loss of capacity to sporulate near the center of the lesion after two sporulation events. E, Extensive necrosis typical of lesions that have sporulated several times. F, Marginal production of sporangia in viable tissue surrounding the necrotic area. 
productivity of lesions in these studies is unclear. Again, these findings are relevant to recent microsatellite-based studies in which certain genotypes either failed to increase in frequency during an epidemic, or were no longer detectable within samples collected later in the growing season $(10,11)$. For example, during repeated (i.e., three or more) short dew periods in which sporulation on extant lesions could occur without opportunity for infection, these lesions and the genotypes they harbor could rapidly decline (Fig. 3). For this reason, estimates of the relative
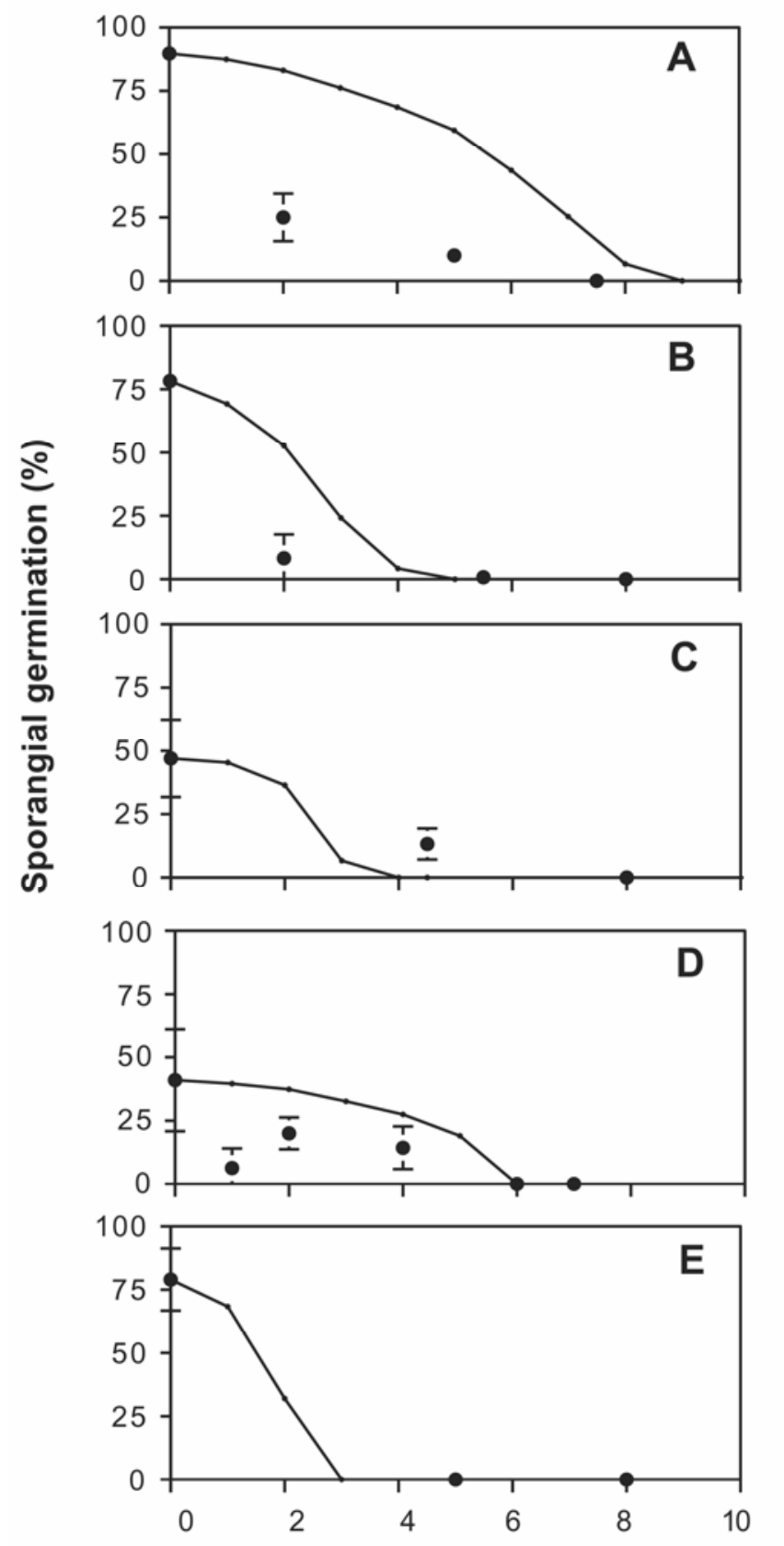

\section{Number of hours sporangia exposed}

Fig. 6. Observed (closed circles) versus predicted (line) germination of Plasmopara viticola sporangia at various times after sunrise during fair weather. Newly-produced sporangia were harvested periodically from lesions borne on foliage of field-grown vines or on foliage of potted vines placed within vine canopies, and germination was assessed in the laboratory. A-E, Harvests on November 4-6, 13, and 28, respectively. Error bars indicate one standard error of the mean for observed germination. Predicted values were generated by DMCast based on hourly temperatures and relative humidity recorded in the vineyard. aggressiveness or fitness of individual genotypes, or of the relative importance of secondary disease development based upon the flux of genotype frequencies over the course of an epidemic, should perhaps involve consideration of how random wetting events might favor or negate the possibility that a cohort of lesions could multiply over a relatively short period of time. In New York, the progress of foliar downy mildew often levels off during midsummer, but can rapidly increase after this period with the return of more favorable weather for disease development (7), despite the apparent absence of new lesions. In addition to possible oospore infections as discussed above, the retention of high spore productivity for the first few sporulation events may also explain this rapid resurgence. In contrast, frequent sporulation events without subsequent opportunity for zoospore release and infection could potentially deplete the supply of productive lesions. This occurs with some frequency in arid, inland, grape-production areas of Australia (P. A. Magarey, unpublished data). Climatic events suitable for sporulation without subsequent infection were uncommon at our research sites in Geneva: They occurred 5, 5, and 8 times during June through August of 2002, 2003, and 2004, respectively, compared to 9,29 , and 35 events of sufficient duration to allow sporulation and infection (M. Kennelly, unpublished data). We do not know the threshold temperature at which $P$. viticola is killed within foliar lesions, but the ability of the pathogen to survive the high temperatures on 15 November 2003 was apparently greater during the incubation period than after symptoms had appeared. This subject warrants additional research, as high temperatures in some viticultural regions may have the potential to significantly slow an epidemic by eradicating the pathogen within pre-existing lesions.

Our observation that sporangia obtained from a dry atmosphere germinated more readily following a brief (15 to $30 \mathrm{~min}$ ) prior exposure to a humid atmosphere is similar to an effect reported by Minogue and Fry (28) in studies of Phytophthora infestans, and indicates a potential source of variation to control in assessments of sporangial viability and to consider when interpreting results of

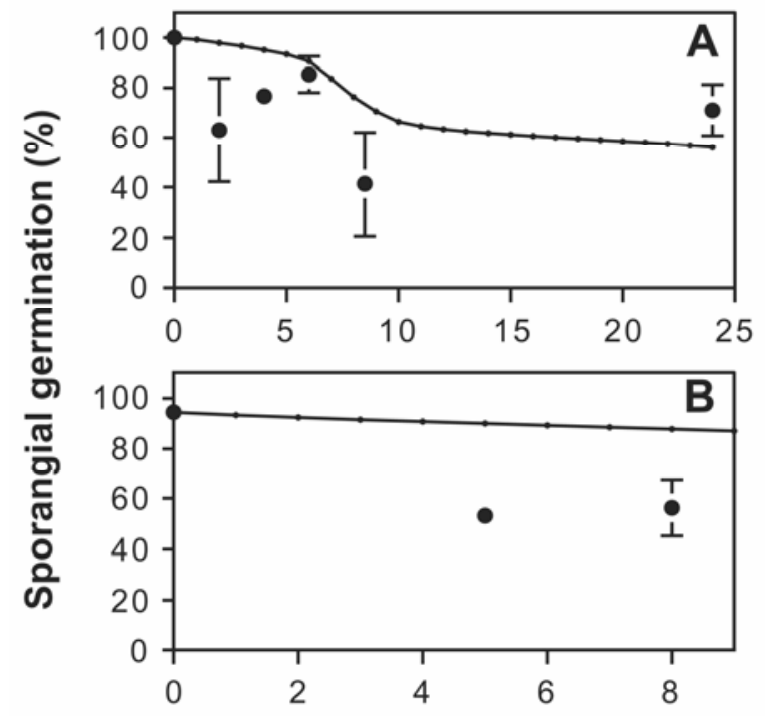

\section{Number of hours sporangia exposed}

Fig. 7. Observed (closed circles) versus predicted (line) germination of Plasmopara viticola sporangia at various times after sunrise during overcast weather. Newly-produced sporangia were harvested periodically from lesions borne on foliage of field-grown vines or on foliage of potted vines placed within vine canopies, and germination was assessed in the laboratory. A-B, Harvests on 20 November and 4 December, respectively. Error bars indicate one standard error of the mean for observed germination. Predicted values were generated by DMCast based on hourly temperatures and relative humidity recorded in the vineyard. 
such studies. The ability of sporangia to partially rehydrate during the typical increase of relative humidity that immediately precedes rainfall may result in greater viability under field conditions than would be deduced from lab studies that did not account for this factor.

DMCast tended to overpredict sporangial viability at discrete time points, which might partially explain the tendency of the model to sometimes overpredict disease when it was evaluated in the field in 1992 and 1993 (29). The observed germination frequency of sporangia was approximately $75 \%$ of the value predicted by DMCast (Fig. 8). However, at a practical level this overprediction of sporangial viability may be of little consequence with respect to daily recommendations generated by the model. During fair weather, observed sporangial viability dropped to negligible or nil levels within 5 to $7 \mathrm{~h}$ after sunrise, whereas predicted viability reached the same levels within 3 to $9 \mathrm{~h}$ (Fig. 6); in both cases, viability declined to nil during the daylight interval following sporulation. Thus the input data for DMCast's calculations (29) for the following evening would be the same whether predicted or observed values were used. Likewise during overcast weather, both predicted and observed viability remained high, and the deviation of predicted from observed viability was not of sufficient magnitude to alter daily recommendations of the model. Similar findings were reported for Bremia lactucae, where sporangial viability decreased quickly in the first few hours of the morning except on the cloudiest days (37).

In summary, together with our earlier work on the ontogenic resistance to downy mildew (18), we can now suggest several modifications to DMCast and similar models of downy mildew used as decision aids in disease management programs. First, the models should reflect the relatively brief period of berry susceptibility to infection (18). Second, based upon the absolute dose of oosporic inoculum at a particular site, it may be advisable to simultaneously monitor conditions for both oosporic and secondary sporangial infection throughout the growing season. Third, the models can now better account for dynamics of lesion productivity based upon the number of sporulation events. Finally, complicated weather-driven models of oospore matur-

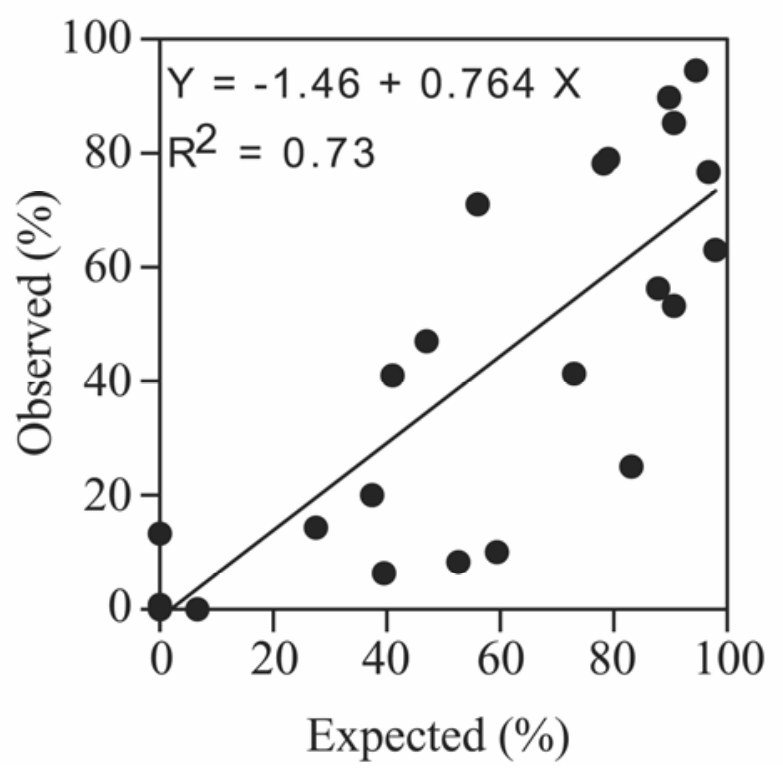

Fig. 8. Observed versus expected germination of Plasmopara viticola sporangia. Newly-produced sporangia were harvested periodically from lesions borne on grapevine leaves on field-grown vines or on foliage of potted vines placed within vine canopies. Harvesting was performed for up to 24 hours with fair weather and for up to 2 days with overcast weather. Germination was then assessed in the lab. Expected germination values were generated by the forecast model DMCast based on hourly temperatures and relative humidity recorded in the vineyard. ation and survival can possibly be replaced by simpler phenology, rainfall, and temperature thresholds to predict initial oosporic infection.

\section{ACKNOWLEDGMENTS}

This research was partially funded by the U.S. Department of Agriculture Cooperative State Research, Education, and Extension Service Viticulture Consortium-East through a grant to Cornell University, NYSAES, under Agreement \#34360-7382, and by the New York State Wine and Grape Foundation. We thank K. Kim for assistance with the DMCast program; and Riverland Wine Grape Industry Development Council, Berri, South Australia, for financial assistance with experiments in Loxton, SA.

\section{LITERATURE CITED}

1. Blaeser, M., and Weltzein, H. 1978. Die Bedeutung von Sporangienbildung, -ausbreitung und -keimung fur die Epidemiebildung von Plasmopara viticola. [German]. Zeitschrift für Pflanzenkrankheiten und Pflanzenschutz 85:155-161.

2. Bleyer, G. 1997. A strategy for the controlled management of Plasmopara viticola. Vitic. Enol. Sci. 52:168.

3. Burkardt, J., and Hill, G. K. 1997. Studies on the epidemiological impact of oospore content in vineyard soils. Vitic. Enol. Sci. 52:136-137.

4. Cortesi, P., and Hill, G. K. 1994. Simulation of grapevine downy mildew epidemics and control with the P. R. O. model. Pages 74-79 in: Proc. Int. Workshop on Grapevine Downy Mildew Modeling, 1st. D. M. Gadoury and R. C. Seem, eds. NY Agric. Exp. Stn. Special Rep. 68.

5. Emmett, R. W., Wicks, T. J., and Magarey, P. A. 1992. Downy mildew of grapes. Pages 90-128 in: Plant Diseases of International Importance: Diseases of Fruit Crops, edited by J. Kumar, H. Chaube, U. S. Singh, and A. Mukhopadhyay. Prentice Hall, Englewood Cliffs, NJ.

6. Fouassier, S., Magnien, C., and Jacquin, D. 1997. MILVIT: A model for the asexual phase of grapevine downy mildew-Results of 4 years of validation. Vitic. Enol. Sci. 52:169-171.

7. Gadoury, D. M., Seem, R. C., and Wilcox, W. F. 1998. Research on the forecasting of downy mildew. Grape Res. News 9:5-6.

8. Gadoury, D.M., Seem, R.C., Wilcox, W.F., and Travis, J.W. 2000. Forecasts of grape downy mildew for New York and Pennsylvania regional IPM programs. Pages 8-11 in: Proc. Int. Workshop on Grapevine Downy and Powdery Mildew, 3rd. P. A. Magarey, S. A Thiele, K. L. Tschirpig, R. W. Emmett, K. Clarke, and R. D. Magarey, eds. South Australia Research and Development Institute (SARDI) Res. Report Ser. No. 50. SARDI, Loxton, Australia.

9. Gehmann, K., 1987. Untersuchungen zur Epidemiologie und Bekämpfung des Falschen Mehltaus der Weinrebe, verursacht durch Plasmopara viticola. [German]. Ph.D. thesis, University of StuttgartHohenheim.

10. Gobbin, D., Jermini, M., Loskill, B., Pertot, I., Raynal, M., and Gessler, C. 2005. Importance of secondary inoculum of Plasmopara viticola to epidemics of grapevine downy mildew. Plant Pathol. 54:522-534.

11. Gobbin, D., Pertot, I., and Gessler, C. 2003. Identification of microsatellite markers for Plasmopara viticola and establishment of high throughput method for SSR analysis. Eur. J. Plant Pathol. 109:153-164.

12. Gregory, C. T. 1912. Spore germination and infection with Plasmopara viticola. Phytopathology 2:235-249.

13. Gregory, C. T. 1915. Studies on Plasmopara viticola (downey mildew of grapes). Pages 126-150 in: Proc. Int. Congr. Vitic.

14. Hill, G. K. 1989. Effect of temperature on sporulation efficiency of oilspots caused by Plasmopara viticola (Berk. \& Curt. ex de Bary) Berl. $\&$ de Toni in vineyards. Vitic. Enol. Sci. 44:86-90.

15. Horner, I. J., and Wilcox, W.F. 1995. SADAMCAP, a technique for quantifying populations of Phytophthora cactorum in apple orchard soils. Phytopathology 85:1400-1408.

16. Huber, B., Bleyer, G., and Kassemeyer, H. H. 2000. Verification of the Freiburg model against Plasmopara viticola by field trials from 19931997. Pages 18-19 in: Proc. Int. Workshop on Grapevine Downy and Powdery Mildew, 3rd. P. A. Magarey, S. A Thiele, K. L. Tschirpig, R. W. Emmett, K. Clarke, and R. D. Magarey, eds. SARDI Research Report Series No. 50. SARDI, Loxton, Australia

17. Kast, W. K., and Stark-Urnau, M. 1999. Survival of sporangia from Plasmopara viticola, the downy mildew of grapevine. Vitis 38:185-186.

18. Kennelly, M. M., Gadoury, D. M., Wilcox, W. F., Magarey, P. A., and Seem, R. C. 2005. Seasonal development of ontogenic resistance to downy mildew in grape berries and rachises. Phytopathology 95:1445-1452.

19. Kennelly, M. M., Seem, R. C., Gadoury, D. M., Wilcox, W. F., and 
Magarey, P. A. 2002. Refinement of DMCast, a predictor of grapevine downy mildew (Plasmopara viticola). Phytopathology 92:S41.

20. Kennelly, M. M., Seem, R. C., Gadoury, D. M., Wilcox, W. F., and Magarey, P. A. 2002. Refinement of DMCast, a predictor of grapevine downy mildew. Pages 36-37 in: Proc. 4th Int. Workshop on Grapevine Downy and Powdery Mildew, Napa, California, 30 Sept. - 4 Oct., 2002. Gadoury, D. M., Gessler, C., Grove, G., Gubler, W. D., Hill, G. K., Kassemeyer, H-H, Kast, W. K., Rumbolz, J, Scott, E. S., eds. University of California Davis Press, Davis.

21. Kennelly, M. M., Seem, R. C., Gadoury, D. M., Wilcox, W. F., and Magarey, P. A. 2003. Integration of lesion productivity and ontogenic resistance of fruit into a warning system for grape downy mildew (Plasmopara viticola). Phytopathology 93:S44.

22. Kennelly, M. M., Seem, R. C., Gadoury, D. M., Wilcox, W. F., and Magarey, P. A. 2004. Survival of grape downy mildew (Plasmopara viticola) sporangia and lesions under field conditions. Phytopathology 94:S50.

23. Kennelly, M. M., Eugster, C., Gadoury, D. M., Smart, C. D., Seem, R. C., Gobbin, D., and Gessler, C. 2004. Contributions of oosporic inoculum to epidemics of grapevine downy mildew (Plasmopara viticola). Phytopathology 94:S50

24. Lafon, R., and Clerjeau, M. 1988. Downy mildew. Pages 11-13 in: Compendium of Grape Diseases, R. C. Pearson and A. C. Goheen, eds. The American Phytopathological Society, St. Paul, MN.

25. Madden, L. V., Ellis, M. A., Lalancette, N., Hughes, G., and Wilson, L. L. 2000. Evaluation of a disease warning system for downy mildew of grapes. Plant Dis. 84:549-554.

26. Magarey, P. A., Wachtel, M. F., Weir, P. C., and Seem, R. C. 1991. A computer-based simulator for rational management of grapevine downy mildew (Plasmopara viticola). Plant Prot. Q. 6:29-33.

27. Mescalchin, E. 1997. Practical experiences in assessment of primary and secondary cycle of Plasmopara on the base of weather monitor data in Trentino (Italy). Vitic. Enol. Sci. 52:157-161.
28. Minogue, K. P., and Fry, W. E. 1981. Effect of temperature, relative humidity, and rehydration rate on germination of dried sporangia of Phytophthora infestans. Phytopathology 71:1181-1184.

29. Park, E. W., Seem, R. C., Gadoury, D. M., and Pearson, R. C. 1997. DMCast: a prediction model for grape downy mildew development. Vitic. Enol. Sci. 52:182-189.

30. Pratt, C. 1988. Grapevine structure and growth stages. Pages 3-7 in: Compendium of Grape Diseases. R. C. Pearson and A. C. Goheen, eds. The American Phytopathological Society, St. Paul, MN.

31. Ronzon-Tran Manh Sung, C., and Clerjeau, M. 1988. Techniques for formation, maturation, and germination of Plasmopara viticola oospores under controlled conditions. Plant Dis. 72:938-941.

32. Rosa, M., Gozzini, B., Orlandini, S., and Seghi, L. 1993. A computer program to improve the control of grapevine downy mildew. Comput. Electron. Agr. $12: 311-322$.

33. Rosa, M., Genesio, R., Gozzini, B., Maracchi, G., and Orlandini, S. 1993. PLASMO: A computer program for grapevine downy mildew development and forecasting. Comput. Electron. Agr. 9:205-215.

34. Seigfried, W. and Bosshard, E. Pages 16-19 in: Proc. Int. Workshop Grapevine Downy Mildew Modeling. 1st. D. M. Gadoury and R. C Seem, eds. NY Agric. Exp. Stn. Spec. Rep. 68

35. Tran Manh Sung, C., Strizyk, S., and Clerjeau, M. 1990. Simulation of the date of maturity of Plasmopara viticola oospores to predict the severity of primary infections in grapevine. Plant Dis. 74:120-124.

36. Wong, F. P., Burr, H. N., and Wilcox, W. F. 2001. Heterothallism in Plasmopara viticola. Plant Pathol. 50:427-432.

37. Wu, B. M., Subbarao, K. V., and van Bruggen, A. H. C. 2000. Factors affecting the survival of Bremia lactucae sporangia deposited on lettuce leaves. Phytopathology 90:827-833.

38. Zachos, D. G. 1959. Recherches sur la biologie et l'epidemiologie du mildiou de la vigne en Grece. [French]. Ann. Inst. Phytopathol. Benaki 2:193-335. 